Gabrijela Blatančić

Logopedski kabinet Verbum Sanum, Zagreb

Ana Bonetti

Sveucilišste u Zagrebu, Edukacijsko-rehabilitacijski fakultet,

Odsjek za logopediju

Tamara Živković-Ivanović

Klinicki bolnicki centar Rebro, Klinika za bolesti uha, nosa i grla i kirurgiju glave i vrata, Odjel za fonijatriju, Zagreb

\section{Objektivna i perceptivna procjena kvalitete glasa kod osoba s jednostranom paralizom glasnice}

\author{
Objective and perceptual assessment of voice \\ quality in persons with unilateral vocal fold \\ paralysis
}

\begin{abstract}
SAŽETAK
Cilj ovog istraživanja je utvrditi glasovne karakteristike kod osoba s jednostranom paralizom glasnice prije i poslije terapije glasa. Procjena glasa odnosi se na perceptivnu procjenu te objektivnu, koja uključuje akustičku analizu i aerodinamičke testove fonacije. U istraživanju je sudjelovalo 9 osoba ženskog spola, u dobi od 27 do 66 godina. Zvučni zapisi spontanog govora korišteni su za perceptivnu procjenu glasa, koju su obavila tri stručna klinička logopeda s iskustvom u području patologije glasa. Snimljeni uzorci fonacije analizirani su u programu Praat za akustičku analizu glasa. Dobiveni podaci obrađeni su deskriptivnom statistikom i neparametrijskim testovima. Rezultati istraživanja pokazuju statistički značajne razlike u perceptivnoj procjeni glasa prije i poslije terapije, $\mathrm{i}$ to kao poboljšanje kvalitete glasa. Prema perceptivnoj procjeni, glas ispitanica poslije terapije bio je normalan ili blago promukao. Razlike su se pokazale i na rezultatima objektivne procjene glasa. Za varijable shimmer, jitter i maksimalno vrijeme fonacije, te su razlike pokazane statistički značajnima. Dobiveni rezultati perceptivne i objektivne procjene potvrđuju vrijednost glasovne terapije za osobe s jednostranom paralizom glasnice. Terapija glasa je neinvazivni oblik rehabilitacije i prvi je izbor osobama kojima je poremećaj glasa najteži simptom paralize glasnice.
\end{abstract}

\begin{abstract}
The aim of this study is to determine the vocal characteristics of patients with unilateral vocal fold paralysis before and after voice therapy. Voice assessment refers to a perceptual and objective evaluation that includes acoustic analysis and aerodynamic voice measurements. This study included 9 female patients aged between 27 and 66 years. Recordings of conversational speech were used for the perceptual evaluation of voice, which was assessed by three speech and language therapists experienced in the field of voice pathology. Recorded samples of phonation were analyzed using the Praat programme for acoustic voice analysis. All collected data was analyzed using descriptive statistics and nonparametric tests. The results of this study demonstrate a significant difference between perceptual evaluations of voice before and after voice therapy in the form of improved voice quality. According to the perceptual evaluation, the voices of all patients were normal or slightly hoarse following therapy. Objective differences were also found before and after voice therapy. For shimmer, jitter and maximum phonation time values, these differences were statistically significant. The results of both perceptual and objective evaluations indicate the importance of voice therapy for people with unilateral vocal fold paralysis. Voice therapy is a noninvasive form of rehabilitation and should be the first choice for patients who experience dysphonia as the most severe symptom of unilateral vocal fold paralysis.
\end{abstract}

\author{
Ključne riječi: \\ jednostrana \\ paraliza glasnice \\ - perceptivna \\ procjena glasa \\ - akustička \\ analiza glasa - \\ disfonija - \\ terapija glasa
}

Keywords: unilateral vocal fold paralysis perceptual evaluation of voice acoustic analysis of voice dysphonia voice therapy 


\section{UVOD}

Jednostrana paraliza glasnice dijagnoza je koja može biti rezultat centralnog oštećenja moždanog debla ili perifernog oštećenja n. vagusa, odnosno njegovih ogranaka, povratnog laringealnog živca i gornjeg laringealnog živca (Kelchner i sur., 1999). Laringealni živci zaduženi su za motoričku i senzoričku inervaciju grkljana. Gotovo sve jednostrane paralize glasnice posljedica su periferne lezije (Katić i Prgomet, 2009). Etiologija je šarolika, uzroci se dijele u četiri skupine: idiopatski, traume, tumori te neurološke i sistemske bolesti (Bothe i sur., 2014). Jednostranu paralizu glasnice najčešće uzrokuje tireoideoktomija, a razlog tomu je anatomski položaj štitne žlijezde pa često dolazi do presijecanja, nagnječenja ili toplinske ozljede povratnog laringealnog živca (Jakelić i sur., 2015). Znatno češće dolazi do paralize lijeve glasnice jer je i lijevi povratni živac duži i time skloniji ozljedama (Ahmad i sur., 2002).

Simptomi jednostrane paralize glasnice variraju, a u trećini slučajeva ostaje asimptomatska (Chandrasekhar i sur., 2013). Disfonija je vodeći simptom kod jednostrane paralize glasnica. Paralizirana glasnica je u većini slučajeva u paramedijalnom položaju (Finck, 2006), što znači da nije u potpunosti adducirana ni abducirana. Glasnica ostaje u tom položaju tijekom disanja i pri pokušaju fonacije. Kod jednostrane paralize glasnice ne može doći do afonije jer Bernoullijev efekt omogućava vibriranje glasnica, odnosno privlači glasnice prema medijalnoj liniji. Glasnice se mogu dodirivati u prednjoj trećini svoje dužine i tako stvaraju glas. Pneumofonija i izrazita šumnost glavne su karakteristike glasa osoba s jednostranom paralizom glasnice, pogotovo u ranoj fazi nakon nastanka paralize. Glas je slab, diplofoničan, smanjenog intenziteta, promukao, a često dolazi do vokalnog napora i gubitka zraka.

Težina disfonije varira ovisno o vrsti ozljede povratnog živca i položaju paralizirane glasnice (Boone i sur., 2005). Nerijetko se javlja i falsetto jer se osoba koristi krikotiroidnim mišićem za moguće postizanje glotalnog zatvaranja (Schindler i sur., 2008). Osim disfonije - česta pojava su disfagija i aspiracija, koja nerijetko dovodi i do upale pluća (Bumber i sur., 2004).

Moguć je spontani oporavak paralizirane glasnice, ali i kompenzacija zdravom glasnicom (Bothe i sur., 2014). Spontani oporavak dogodi se kod, otprilike, polovice osoba - obično u prvih devet do dvanaest mjeseci nakon paralize (Boone i McFarlane, 2000). Prvi korak odabira terapije je procjena paralize glasnice. Terapija može biti kirurška ili konzervativna, odnosno vokalna terapija (Gardner i Benninger, 2003). Ključno je da se vokalnom terapijom počne što prije nakon nastanka disfonije - zbog paralize glasnice. Terapija glasa djeluje na jačanje vokalne muskulature i poboljšanje tehnike govora. Kod većine pacijenata, čak $75 \%$, zadovoljavajući je oporavak nakon terapije glasa: kvaliteta glasa je bolja zbog adekvatne glotalne kompenzacije (Bothe i sur., 2014). Najčešće primijenjene tehnike u logopedskoj terapiji jednostrane paralize glasnice su tvrda glotalna ataka, abdominalno disanje, opuštanje glave i vrata, treperenje usnicama i jezikom, rezonantni glas, metoda naglaska, fonacija na udisaju te laringealna masaža (Schindler i sur., 2008; Boone i sur., 2005). Time se također sprečava i aspiracija. Međutim, može doći i do loših kompenzatornih navika, odnosno neki pacijenti razviju hiperfunkcionalna glasovna ponašanja. Terapija glasa je neinvazivna te se uglavnom primjenjuje kod svih pacijenata $s$ disfonijom. Time se smanjuje potreba za invazivnom kirurgijom.

Cilj ovog istraživanja je perceptivnom te objektivnom procjenom glasa utvrditi glasovne karakteristike kod osoba s jednostranom paralizom glasnice prije i poslije terapije i time kvantificirati učinak vokalne terapije.

\section{METODE}

\section{Uzorak}

U ovom istraživanju sudjelovalo je 9 ispitanica, u dobi od 27 do 66 godina (srednja dob 46,11). Kriteriji za oblikovanje uzorka bili su: pripadnost ženskom spolu i jednostrana paraliza glasnice. Kriterij pripadnost ženskom spolu postavljen je zato što je jednostrana paraliza glasnice češća kod žena (Cantarella i sur., 2016). U ovom istraživanju mjerila se kvaliteta glasa isključivo prije i poslije logopedske terapije glasa, u koju se mogu uključiti jedino osobe s jednostranom paralizom glasnice. Sve su ispitanice imale jednostranu paralizu glasnice, a dijagnozu je postavio specijalist otorinolaringolog. Uzroci jednostrane paralize glasnice kod ispitanica bili su totalna tireoidektomija $(\mathrm{N}=3)$, lobektomija $(\mathrm{N}=2)$, idiopatska etiologija $(\mathrm{N}=2)$, tumor medijastinuma $(\mathrm{N}=1)$ te kirurgija cervikalne kralježnice $(\mathrm{N}=1)$.

\section{Mjerni instrumenti i varijable}

Aerodinamički testovi fonacije odnose se ponajprije na maksimalno vrijeme fonacije. Maksimalno vrijeme fonacije vokala /a/ jednostavan je klinički test za odredivanje glotalne funkcije pri fonaciji.

Akustička analiza glasa provedena je u PRAAT programu. Ovaj oblik procjene često je primijenjen zbog svoje jednostavnosti, dostupnosti, objektivnosti u dijagnostici, ali i praćenju pacijenata (Bonetti, 2011). U istraživanju su procjenjivani akustički parametri:

1. $\mathrm{F} 0$ - osnovni laringealni ton $(\mathrm{Hz})$

2. JITT - varijacije fundamentalne frekvencije $(\%)$

3. SHIMM - fluktuacija amplitude zvučnog signala (dB)

4. HNR - omjer harmoničnog i šumnog dijela spektra (dB)

Perceptivnu procjenu glasa činila je procjena ocjene $G$ (opći stupanj disfonije). Zvučni zapis spontanog govora svake ispitanice ocijenila su tri logopeda ocjenama od 0 do 3 - gdje 0 označava normalan glas, 1 blagu disfoniju, 2 umjerenu disfoniju, a 3 označava jaku disfoniju. Budući da su time dobivene po tri ocjene za $G$ parametar, izračunana je srednja ocjena za svaku ispitanicu.

\section{Način prikupljanja podataka}

Odabiru ispitanica pristupilo se na Odjelu za fonijatriju Kliničkog bolničkog centra Rebro, gdje je etičko povjerenstvo odobrilo nacrt ovog istraživanja. Podaci su prikupljeni individualno za svaku ispitanicu iz postojeće 
medicinske dokumentacije: dob, primarna dijagnoza (ako postoji) i sekundarna dijagnoza (paraliza glasnice). Procjena svake ispitanice obavljena je u dvije vremenske točke neposredno prije i poslije završene logopedske terapije. Sve ispitanice bile su uključene $\mathrm{u}$ individualnu logopedsku terapiju, u trajanju od 3 do 6 mjeseci. Terapija se provodila svaki ili svaki drugi dan. O završetku logopedske terapije odlučivalo se na osnovi: 1. zadovoljstva pacijenta kvalitetom glasa, 2. zadovoljstva logopeda rezultatom terapije, 3. ORLpregleda, kojim se utvrđuje kompenzacija zdravom glasnicom, to jest poboljšana addukcija glasnica.

Prikupljanje zvučnih zapisa odvijalo se u zvučno izoliranoj sobi - kabinetu za fonetiku i logopediju Odjela za fonijatriju Kliničkog bolničkog centra Rebro. Mikrofon je bio postavljen svim ispitanicama na jednakoj udaljenosti od usta (oko $25 \mathrm{~cm}$ ). Opći stupanj disfonije procijenjen je kod svih ispitanica prije i poslije terapije. Od ispitanica je traženo da svojom habitualnom visinom i glasnoćom kažu nešto o sebi, te je takav spontani govor snimljen u zvučno izoliranoj prostoriji i potom obrađen. Procjenu su obavila tri stručna logopeda s višegodišnjim iskustvom u području patologije glasa. Procjena se radila individualno, gdje je svaki procjenjivač svaki zvučni zapis spontanog govora mogao procijeniti ocjenama od 0 do 3.

$\mathrm{Na}$ osnovi zvučnog zapisa maksimalne fonacije vokala /a/ analizirani su akustički parametri i vrijeme trajanja maksimalne fonacije. Ispitanicama je demonstrirano izvođenje fonacije vokala /a/ i dana uputa da foniraju svojom habitualnom visinom i glasnoćom.

\section{REZULTATI I RASPRAVA}

Tablica 1 prikazuje rezultate testa slaganja triju neovisnih procjenjivača. Test slaganja pokazuje statistički značajno slaganje između perceptivne procjene procjenjivača prije terapije i perceptivne procjene procjenjivača poslije terapije. Budući da postoji umjereno do visoko slaganje među ispitivačima, te je statistički značajno, izračunana je srednja ocjena za svaku ispitanicu.

Tablica 2 prikazuje osnovne statističke podatke za zavisne varijable perceptivne procjene prije i poslije terapije. Vidljivo je da se procjena parametra $G$ prije i poslije terapije razlikuje, što pokazuje aritmetička sredina rezultata, standardna devijacija te najmanji $i$ najveći rezultat. Isti pokazatelji upućuju na perceptivno bolju kvalitetu glasa poslije terapije.

Tablica 3 pokazuje statistički značajnu razliku između perceptivne procjene prije i poslije terapije. Statistički značajna razlika između perceptivne procjene prije i poslije terapije pokazana je i u dosadašnjim istraživanjima (Schindler i sur., 2008; Cantarella i sur., 2010). Ovakav rezultat ne iznenađuje jer približavanjem paralizirane glasnice medijalnoj liniji glas dobiva na jačini te je manje šuman i promukao. Srednja vrijednost ocjene parametra $G$ prije terapije upućuje na glas loše kvalitete (tablica 2). Poslije terapije srednja vrijednost je znatno niža te odgovara zdravom glasu. Maksimalna ocjena parametra $G$ prije terapije je najviša ocjena 3 , što upućuje na postojanje jake disfonije, a poslije terapije ocjena 1, što odgovara blagoj disfoniji. Budući da kod paralize jedne glasnice postoji nesposobnost glotalnog zatvaranja, terapijom glasa želi se postići potpuno ili približno potpuno glotalno zatvaranje. Prije terapije, paralizirana glasnica je obično položena dalje od medijalne linije te je glas tada slabiji i šuman. Kada je glasnica bliže medijalnoj liniji, glas je manje šuman i dobiva na jačini odnosno intenzitetu. Stoga se terapijom glasa ostvaruje napredak u obliku potpunog ili približno potpunog glotalnog zatvaranja, na što upućuju i ocjene perceptivne procjene poslije terapije.

Tablica 1. Intraklasna korelacija slaganja procjenjivača

\begin{tabular}{|l|c|c|}
\hline & ICC & p vrijednost \\
\hline G & 0,926 & 0,000 \\
\hline G1 & 0,640 & 0,042 \\
\hline
\end{tabular}

Napomena: G=opći stupanj disfonije prije terapije; G1=opći stupanj disfonije poslije terapije; ICC=intraklasna korelacija

Tablica 2. Deskriptivni podaci zavisnih varijabli perceptivne procjene glasa prije i poslije terapije

\begin{tabular}{|l|c|c|c|c|c|}
\hline & N & M & SD & MIN & MAX \\
\hline G & 9 & 1,99 & 0,71 & 1 & 3 \\
\hline G1 & 9 & 0,33 & 0,37 & 0 & 1 \\
\hline
\end{tabular}

Napomena: $G=$ opći stupanj disfonije prije terapije; $G 1=$ opći stupanj disfonije poslije terapije

Tablica 3. Rezultati Wilcoxonova testa ekvivalentnih parova za zavisne varijable perceptivne procjene glasa

\begin{tabular}{|l|c|}
\hline Zavisne varijable & p vrijednost \\
\hline G i G1 & 0,008 \\
\hline
\end{tabular}

Napomena: $G=$ opći stupanj disfonije prije terapije; $G 1=$ opći stupanj disfonije poslije terapije

Maksimalno vrijeme fonacije mjereno prije terapije glasa u rasponu je od 3 do 13 sekundi, a poslije terapije od 6 do 21 sekundu (tablica 4). Poslije terapije srednja vrijednost iznosi 13,33 sekundi, što je znatno poboljšanje. Poboljšanje u mjerenju maksimalnog vremena fonacije pokazuje se statistički značajnim na razini značajnosti $\mathrm{p}<0,05$ (tablica 5). Niže vrijednosti MVF prije terapije proizlaze iz glotalne inkompetencije, odnosno vrijednost MVF povezuje se s veličinom procijepa kod glotalnog zatvaranja. Poslije terapije glasa postignuto je duže vrijeme fonacije vokala /a/, što upućuje na bolje glotalno zatvaranje, odnosno manji procijep među glasnicama.

Tablica 6 prikazuje osnovne statističke podatke za varijable akustičke analize glasa prije terapije. Fundamentalna frekvencija je izrazito širokoga raspona, a visoka standardna devijacija upućuje na veliku raspršenost rezultata oko srednje vrijednosti. Aritmetička sredina fundamentalne frekvencije glasa svih ispitanica u rasponu je normalnog glasa za ženski spol (Jesus i sur., 2015), dok raspon F0 prelazi granice raspona F0 normalnog ženskoga glasa. Više vrijednosti varijacija frekvencije osnovnog laringealnog tona, odnosno 
jittera prije terapije nisu neobične jer paraliza jedne glasnice dovodi do asimetrije na razini glotisa i time stvara promjene u frekvenciji vibracija glasnica. Takve povišene vrijednosti odgovaraju glasu lošije kvalitete. Slično, zbog asimetrije dolazi do nepravilnosti u amplitudi vibracija glasnica te se $i$ vrijednost fluktuacije amplitude unutar fonacije povećava. Više vrijednosti shimmera upućuju na promukli glas. Širi raspon vrijednosti harmoničnog i šumnog dijela spektra (HNR) upućuju na varijabilnost parametra kod žena s jednostranom paralizom glasnice, koje su sudjelovale $u$ ovom istraživanju.

Tablica 4. Deskriptivni podaci zavisne varijable maksimalno vrijeme fonacije

\begin{tabular}{|l|c|c|c|c|c|}
\hline & N & M & SD & MIN & MAX \\
\hline MVF & 9 & 7,77 & 3,52 & 3 & 13 \\
\hline MVF1 & 9 & 13,33 & 5,04 & 6 & 21 \\
\hline
\end{tabular}

Napomena: $\quad M V F=$ maksimalno vrijeme fonacije prije terapije; MVF1 $=$ maksimalno vrijeme fonacije poslije terapije

Tablica 5. Rezultati Wilcoxonova testa ekvivalentnih parova za zavisnu varijablu - maksimalno vrijeme fonacije

\begin{tabular}{|l|c|}
\hline Zavisne varijable & p vrijednost \\
\hline MVF i MVF1 & 0,021 \\
\hline
\end{tabular}

Napomena: $\quad M V F=$ maksimalno vrijeme fonacije prije terapije; MVF1=maksimalno vrijeme fonacije poslije terapije

Tablica 6. Deskriptivni podaci zavisnih varijabli akustičke analize glasa prije terapije

\begin{tabular}{|l|c|c|c|c|c|}
\hline & N & M & SD & MIN & MAX \\
\hline F0 & 9 & 203,57 & 46,99 & 106,62 & 273,32 \\
\hline JITT & 9 & 0,93 & 0,66 & 0,29 & 2,41 \\
\hline SHIMM & 9 & 0,54 & 0,38 & 0,15 & 1,21 \\
\hline HNR & 9 & 19,77 & 7,54 & 6,74 & 27,48 \\
\hline
\end{tabular}

Napomena: $\quad \mathrm{F} 0=$ osnovni laringealni ton $(\mathrm{Hz}) ; \quad$ JITT $=$ varijacije fundamentalne frekvencije (\%); SHIMM=fluktuacija amplitude zvučnog signala $(\mathrm{dB}) ; \mathrm{HNR}=$ omjer harmoničnog $\mathrm{i}$ šumnog dijela spektra $(\mathrm{dB})$

Tablica 7 prikazuje osnovne statističke podatke varijabli akustičke analize glasa poslije terapije. Raspon fundamentalne frekvencije poslije terapije je smanjen i približno je u granicama normalnih vrijednosti. Srednja vrijednost F0 također je snižena. Poslije terapije maksimalna vrijednosti jittera i shimmera odgovaraju vrijednostima zdravih glasova. Najniža i najviša vrijednost odnosa harmoničnog prema šumnom dijelu spektra također odgovara preporučenim vrijednostima.

Iz tablice 8 vidljivo je da je dobivena statistički značajna razlika na varijablama jitter $i$ shimmer mjerenima prije $i$ poslije terapije.

Istraživanje, koje su proveli Jesus i sur. (2014) te Chowdhury i sur. (2013), pokazuje da nema statistički značajnih razlika u fundamentalnoj frekvenciji kod osoba s jednostranom paralizom glasnice i kontrolne skupine za oba spola. Međutim, autori upućuju na višu vrijednost standardne devijacije $\mathrm{F} 0 \mathrm{u}$ skupini s jednostranom paralizom glasnice, što je veći raspon F0 nego kod kontrolne skupine.

Tablica 7. Deskriptivni podaci zavisnih varijabli akustičke analize glasa poslije terapije

\begin{tabular}{|l|c|c|c|c|c|}
\hline & N & M & SD & MIN & MAX \\
\hline F01 & 9 & 189,07 & 21,36 & 159,92 & 217,92 \\
\hline JITT1 & 9 & 0,43 & 0,17 & 0,21 & 0,74 \\
\hline SHIMM1 & 9 & 0,21 & 0,06 & 0,12 & 0,34 \\
\hline HNR1 & 9 & 23,75 & 1,99 & 20,17 & 27,89 \\
\hline
\end{tabular}

Napomena: F01=osnovni laringealni ton $(\mathrm{Hz}) ; \quad$ JITT1=varijacije fundamentalne frekvencije (\%); SHIMM1=fluktuacija amplitude zvučnog signala $(\mathrm{dB}) ; \mathrm{HNR} 1=$ omjer harmoničnog i šumnog dijela spektra $(\mathrm{dB})$

Tablica 8. Rezultati Wilcoxonova testa ekvivalentnih parova za zavisne varijable akustičke analize glasa, gdje varijable F0, JITT, SHIMM i HNR označavaju mjerenje prije terapije glasa, a F01, JITT1, SHIMM1 i HNR1 označavaju mjerenje poslije terapije glasa

\begin{tabular}{|l|c|}
\hline Zavisne varijable & p vrijednost \\
\hline F0 i F01 & 0,173 \\
\hline JITT i JITT1 & 0,038 \\
\hline SHIMM i SHIMM1 & 0,011 \\
\hline HNR i HNR1 & 0,214 \\
\hline
\end{tabular}

Napomena: $\quad \mathrm{F} 0={ }_{\text {osnovni laringealni }}$ ton $(\mathrm{Hz}) ; \quad$ JITT $=$ varijacije fundamentalne frekvencije (\%); SHIMM=fluktuacija amplitude zvučnog signala $(\mathrm{dB}) ; \mathrm{HNR}=$ omjer harmoničnog $\mathrm{i}$ šumnog dijela spektra $(\mathrm{dB})$

Statistički značajna razlika dobivena je na varijablama jitter i shimmer prije i poslije terapije, što je u skladu s dosadašnjim istraživanjima (Schindler i sur., 2008; Cantarella i sur., 2010).

Nakon terapije, kojom se postiže addukcija glasnica (potpuna ili djelomično potpuna), vrijednosti jittera i shimmera se smanjuju. Niže vrijednosti tih dvaju parametara slažu se i s rezultatima perceptivne procjene, odnosno upućuju na bolju kvalitetu glasa i važnost terapije glasa. Vrijednosti akustičkog parametra - omjer šumnog i harmoničnog dijela spektra mjerenog poslije terapije, također upućuju na zvučniji i manje šuman glas, iako nije dobivena statistički značajna razlika kao u dosadašnjim istraživanjima (Schindler i sur., 2008; Cantarella i sur., 2010). U istraživanju Cantarella i sur. (2010) mjerena je vrijednost HNR-a, odmah po nastupu paralize glasnice te nakon tri mjeseca terapije. Pokazano je da kod ranijeg mjerenja postoji više šuma u glasu nego u mjerenju tri mjeseca nakon nastupa paralize glasnice. To se može objasniti minimalnom spontanom glotalnom kompenzacijom. Treba uzeti u obzir da u ovom istraživanju pri odabiru uzorka kriterij nije bilo razdoblje od dijagnoze do početka terapije glasa. Duže 
razdoblje između nastupa paralize glasnice i terapije glasa moguće je doveo do spontane kompenzacije kod ispitanica koje su pri mjerenju imale omjer signal - šum normalnih vrijednosti. Također, mali uzorak ispitanika može biti razlog zašto nema statistički značajne razlike na ovoj varijabli u dvama mjerenjima.

\section{ZAKLJUČAK}

Poremećaji glasa zbog jednostrane paralize glasnice znatno utječu na kvalitetu života pojedinca. Osim poremećaja glasa mogu se javiti i drugi simptomi - disfagija i aspiracija - koji mogu biti opasni za život osobe. Ako je najteži simptom jednostrane paralize glasnice poremećaj glasa, osobi se preporučuje glasovna terapija kao neinvazivni oblik rehabilitacije.

Iako je kod svih ispitanica jedna glasnica ostala paralizirana i poslije terapije, laringoskopijom je utvrđen napredak u glotalnom zatvaranju - odnosno postignuta je kompenzacija kontralateralnom glasnicom i promjenom položaja paralizirane glasnice. Osim što je napredak vidljiv endoskopski, rezultati procjene kvalitete glasa također pokazuju značajno poboljšanje kvalitete glasa kod ispitanica s jednostranom paralizom glasnica. Kao metode procjene bile su odabrane perceptivna i objektivna procjena glasa. Rezultati istraživanja pokazuju statistički značajne razlike u obliku poboljšanja kvalitete glasa prema perceptivnoj procjeni, ali i objektivnoj procjeni. Razlike u maksimalnom vremenu fonacije te perturbacijskim mjerama, jitteru i shimmeru, pokazale su se statistički značajnima. Iznimke su varijable omjer signal - šum i fundamentalna frekvencija, na kojima nisu pokazane statistički značajne razlike. Međutim, deskriptivna statistika ipak pokazuje napredak i na navedenim varijablama poslije terapije. Iako akustički parametri poslije terapije ne pokazuju patološke vrijednosti pa bi upućivali na uredan glas, perceptivna je procjena da postoji blaga promuklost u nekim glasovima.

$\mathrm{U}$ daljim istraživanjima trebalo bi provesti subjektivnu metodu samoprocjene među ispitanicima kako bi se dobili odgovori na neka, možda, neodgovorena pitanja i stekao uvid kako glas, koji je posljedičan paralizi glasnice, može utjecati na kvalitetu života. Istraživanje je obuhvatilo mali broj ispitanika pa postoji potreba za daljim ispitivanjem ove problematike, u koju treba uključiti oba spola.

\section{LITERATURA}

1) Ahmad, S., Muzamil, A., Lateef, M. (2002). A study of incidence and etiopathology of vocal cord paralysis. Indian Journal of Otolaryngology - Head and Neck Surgery, 54 (4), 294 296.

2) Bonetti, A. (2011). Multidimenzionalna struktura disfonije. Doktorska disertacija. Zagreb: Sveučilište u Zagrebu, Edukacijsko-rehabilitacijski fakultet.

3) Boone, D.R. i McFarlane, S.C. (2000). The voice and voice therapy, 6th edition. Needham Heights: Pearson Education Co.

4) Boone, D.R., McFarlane, S.C., Von Berg, S.L. (2005). The voice and voice therapy, 7th edition. Boston: Allyn \& Bacon.
5) Bothe, C., Lopez, M., Quer, M., Leon, X., Garcia, J., Lop, J. (2014). Aetiology and treatment of vocal fold paralysis: retrospective study of 108 patients. Acta Otorrinolaringologica Espanola, 65 (4), 225-230.

6) Bumber, Ž., Katić, V., Nikšić-Ivančić, M., Pegan, B., Petric, V., Šprem, N. (2004). Otorinolaringologija. Zagreb: Naklada Ljevak.

7) Cantarella, G., Viglione, S., Forti, S., Pignataro, L. (2010). Voice therapy for laryngeal hemiplegia: The role of timing of initiation of therapy. Journal of rehabilitation Medicine, 42, 442-446.

8) Cantarella, G., Dejonckere, P., Galli, A., Ciabatta, A., Gaffuri, M., Pignataro, L., Torretta, S. (2016). A retrospective evaluation of the etiology of unilateral vocal fold paralysis over the last 25 years. European Archives of Otorbinolaryngology, 1-7.

9) Chandrasekhar, S.S., Randolph, G.W., Seidman, M.D., Rosenfeld, R.M., Angelos, P., Barkmeier-Kraemer, J., Benninger, M.S., Blumin, J.H., Dennis G., Hanks, J., Haymart, M.R., Kloos, R.T., Seals, B., Schreibstein, J.M., Thomas, M.A., Waddington, C., Warren, B., Robertson, P.J. (2013). Clinical practice guideline: Improving voice outcomes after thyroid surgery. Otolaryngology-Head and Neck Surgery, 148, 1-37.

10)Chowdhury, K., Saha, S., Saha, V.P., Pal, S., Chatterjee, I. (2013). Pre and post operative voice analysis after medialiaztion thyroplasty in cases of unilateral vocal fold paralysis. Indian Journal of Otolaryngology and Head and Neck Surgery, 65 (4), 354-357.

11) Finck C. (2006). Laryngeal dysfunction after thyroid surgery: diagnosis, evaluation and treatment. Acta Chirurgica Belgica, 106, 378-387.

12) Gardner, G.M., Benninger, M.S. (2003). Vocal fold paralysis. U: Rubin, J.S., Sataloff, R.T., Korovin, G.S. (ur.). Diagnosis and treatment of voice disorders, Second edition (str. 435456). New York: Delmar Learning.

13) Jakelić, A., Bonetti, A., Šimunjak, B. (2015). Akustička procjena i samoprocjena glasa žena s bolestima štitnjače. Logopedija, 5 (1), 9-14.

14) Jesus, L., Martinez, J., Hall, A., Ferreira, A. (2015). Acoustic correlates of compensatory adjustments to the glottic and supraglottic structures in patients with unilateral vocal fold paralysis. BioMed Research International, 1-9.

15) Katić, V., Prgomet, D. (2009). Otorinolaringologija i kirurgija glave i urata: prirućnik. Zagreb: Naklada Ljevak.

16) Kelchner, L.N., Stemple, J.C., Gerdeman, B., Le Borgne, W., Adam, S. (1999). Etiology, pathophysiology, treatment chioces, and voice results for unilateral adductor vocal fold paralysis: A 3-year retrospective. Journal of Voice, 13 (4), 592-601.

17) Schindler, A., Bottero, A., Capaccio, P., Ginocchio, D., Adorni, F., Ottaviani, F. (2008). Vocal improvement after voice therapy in unilateral vocal fold paralysis. Journal of Voice, 22 (1), 113-118. 